\title{
DECEPTIVE DEVELOPERS, COMPETITIVE ZONING BOARDS, AND THE ASYMMETRY OF INFORMATION
}

\author{
Leon Taylor*
}

\begin{abstract}
Suppose that a developer applies to a zoning board for approval of his proposed project. He might understate the infrastructural costs of the project in order to trick the board into approving it. This chicanery later will saddle the community with unexpectedly high costs. Its fiscal loss could be heavy if it competes with its neighbors for economic development. Competition prevents the board from extracting from the project a location rent that would cover unexpectedly high infrastructural costs. The board can eliminate the developer's incentive to mislead it by telling him that he will have to pay at least half of the infrastructural costs. Curiously, requiring him to pay all costs can reduce the loss of consumer surplus that is due to his exercise of market power in the private market. The analysis assumes that the board tries to maximize the community's monetary gain from the project.
\end{abstract}

\section{INTRODUCTION}

Because many localities lack planning expertise in zoning matters, they must rely on the developer's estimates of the infrastructural costs of any proposed project. Naturally, the developer might understate those costs in order to gain zoning approval: ${ }^{1}$

In Florida's Flagler County (population 4,500) an ITT subsidiary has been laying out lots for a new community of 750,000 people. The 100,000 -acre development accounts for one-third of all the land in the county. When localities are confronted with plans of this magnitude, backed up by companies with considerable financial strength and expensive hired planning talent, they find themselves unable to properly evaluate them or to exact the appropriate concessions from the developer. Lacking their own professional staff, they must rely on data generated by the developer, who is usually quick to point out the economic advantages of development, while glossing over its long-run costs (Healy 1976).

The locality might approve the seemingly tax-rich project in haste if it fears that the developer will take it to another locality.

\footnotetext{
* Assistant Professor of Economics, Tulane University. For valuable comments, I thank John H. Cumberland, Marie Howland, Alan J. Krupnick, Andrew B. Lyon, Wallace E. Oates, Karen Palmer, Alison M. Rose, Robert M. Schwab, other scholars at Resources for the Future, and the referees and editors of this journal. I derived this paper from my dissertation, supervised by Wallace Oates at the University of Maryland, College Park.
} 
The literature on economic competition between jurisdictions has not delved deeply into this problem. One strand of the literature suggests that competition between jurisdictions can allocate resources efficiently, much like competition between firms (Oates and Schwab 1988). But this theory usually assumes perfect information. The zoning problem suggests that asymmetry of information can prevent jurisdictional competition from achieving allocative efficiency.

To many, asymmetric information justifies state intervention in local decisions concerming land use. The state has a larger staff that can digest the developer's data more thoroughly, and who are not under such intense, competitive pressure to make a quick decision. ${ }^{2}$ Vermont adopted state land-use controls largely on the argument that townships employed few planners and consequently had to accept information from the developers on faith (Healy 1976).

An alternative argument is that local officials need not yield their standing in land-use issues. They do need to tell the applying developer that if his project is approved, he will have to pay at least part of the costs of building and maintaining roads, classrooms, sewers, water mains, and other utilities required by the development. Requiring the developer to pay these "impact fees" induces him to minimize infrastructural costs. It also weakens his incentive to understate those costs.

The purpose of this paper is to analyze the theoretical effects of impact fees on the developer's incentive to understate infrastructural costs. It will develop a model of a developer who seeks project approval from the zoning board of a small, perhaps rural, jurisdiction.

The developer and the zoning board must set certain prices. The developer wants to sell units of his project on the private market at a price that maximizes his profit. The project's location gives the developer market power. For instance, a retirement resort in the mountains of Vermont would command a locational premium over a resort in a dingy city. The jurisdiction's residents want the board to extract a locational rent from the developer, which they will divide equally among themselves. This fee resembles the direct payment in the Fischel (1975) model of suburban competition for industry.

Suppose that the zoning board expects the jurisdiction to make money from the project. It will approve the project and charge the developer a location fee for every unit built. The board will not approve projects that it expects to go bankrupt.

The jurisdiction will build enough infrastructure for the project to prevent further congestion. Suppose that the jurisdiction's schools average 22 students per class. As the project comes on line, the jurisdiction would expand its schools until class size returns to 22 students. The board could then charge the developer an impact fee. 
The board seeks the combination of location and impact fees that will maximize its revenues from the project, net of its infrastructural costs, subject to two constraints:

(1) Only the developer knows how much the additional infrastructure will cost. For instance, he knows how many daily trips his project will generate on local roads for households of varying ages and sizes. If his application discloses this information, the board might decide that the expense of expanding the roads outweighs the project's value. However, the developer might persuade the board that his project will attract only elderly households, which will not strain the capacity of the existing roads.

The board's uncertainty over infrastructural costs is ex ante, not ex post. Once construction begins, the board will observe actual costs. The board and the developer will honor their agreement to share those costs. ${ }^{3}$

(2) The board might have to compete with other communities for the project. The keener the competition, the less the board can extract in location rent from the developer.

The model can be compared to a four-round game. In round one, the board reveals its impact fee to the developer and the developer tells the board what infrastructural costs to expect. In round two, the board selects its location fee and the developer simultaneously selects his unit price. ${ }^{4}$ In round three, the board approves the project and the developer announces the actual cost. In round four, the board and the developer pay their costs and receive their profits. The game is not repeated. 5

This paper draws upon the theory of designing regulatory policy with limited information. Two good surveys are Besanko and Sappington (1987) and Sappington and Stiglitz (1987). In the regulatory problem, the regulator seeks to maximize consumer surplus, subject to the constraint that the firm earn normal profits. Since the regulator cannot observe costs, the firm can increase profits by overstating costs and thus produce less than society would prefer. Therefore, the regulator must draw up a tax schedule that will induce the firm to reveal its costs.

In regard to the zoning problem, the firm can increase profits by understating costs, thus producing more than the community would prefer. The question is whether an impact fee would induce the firm to tell the truth about its costs.

Section II presents the paper's basic model. The developer can choose the level of infrastructural cost. If the developer knows that he will not have to pay any infrastructural costs, he might understate expected costs in his application to the board. When he knows that he must pay some costs, he will try to minimize them. Curiously, requiring the developer to pay all infrastructural costs can reduce the welfare loss that is due to his exercise of market power. 
The next section considers the case in which the developer must take infrastructural costs as given, and whether he might then have an incentive to understate costs even when he knows that he will have to pay impact fees.

The model is normative, but Section III discusses the practical value of modeling a zoning board as a profit-maximizer. Section IV presents conclusions and indicates directions for future research.

\section{THE BASIC MODEL ${ }^{6}$}

In the following model, Subscript 1 indicates the developer and Subscript 2, the zoning board. The developer and the zoning board know that if the project is built, the developer can sell $\mathrm{D}_{1}$ units at price $\mathrm{p}_{1}$, where

$$
\mathrm{D}_{1}=\mathrm{a}-\mathrm{bp}_{1} \quad \mathrm{a}>0 \quad \mathrm{~b}>0
$$

For simplicity, I make three assumptions. First, the demand function (a stock) is linear. ${ }^{7}$ Second, the project has only infrastructural costs. Third, marginal infrastructural costs are constant. Indeed, there are only two possibilities. If each unit requires a low level of infrastructure, $\mathrm{L}$, the marginal infrastructural cost is $c^{L}$. If each unit requires a high level of infrastructure, $\mathrm{H}$, the marginal infrastructural cost is $\mathrm{c}^{\mathrm{H}}$, where $\mathrm{c}^{\mathrm{L}}<\mathrm{c}^{\mathrm{H}} 8$

The developer can choose whether the infrastructural level will be $\mathrm{L}$ or $\mathrm{H}$. For instance, by installing faucets that conserve water, he can limit the needed expansion of the community's waterworks. The board assumes that there is an $x$ percent chance that the marginal cost will be $c^{\mathrm{L}}$ and a (1-x) percent chance that it will be $c^{\mathrm{H}}$, where $\mathrm{x}$ is a continuous variable, $0 \leq \mathrm{x} \leq 1$. The board's estimate of the marginal cost, $c^{\mathrm{e}}=x c^{\mathrm{L}}+(1-\mathrm{x}) \mathrm{c}^{\mathrm{H}}$, is also a continuous variable, $c^{\mathrm{L}} \leq c^{\mathrm{e}} \leq \mathrm{c}^{\mathrm{H}}$. By influencing $x$, the developer determines $c^{e}$. The actual marginal cost is $c$. This is either $\mathrm{c}^{\mathrm{L}}$ or $\mathrm{c}^{\mathrm{H}}$, whichever the developer chooses.

To assess the developer's proposal, the board will estimate its expected net benefits to the community. i.e., the known benefits (the location fee times the number of units built) minus the expected infrastructural costs.

Case 1: Developer pays no infrastructural costs. Suppose that the board agrees to pay all infrastructural costs, but will charge the developer a location fee of $\mathrm{p}_{2}$ per unit. The board expects to gain

$$
\pi_{2}=\left[p_{2}-c^{e}\right]\left[a-b p_{1}\right]
$$

The developer's profit will be:

$$
\pi_{1}=\left[p_{1}-p_{2}\right]\left[a-b p_{1}\right]
$$


We seek a Nash equilibrium. Each agent maximizes profits, subject to the constraint that the other agent maximizes profits. The zoning board charges $\mathrm{p}_{2}^{*}$. The developer chooses $\mathrm{p}_{1}$ to maximize (3), subject to $\mathrm{p}_{2}=\mathrm{p}_{2}{ }^{*}$. Differentiate (3) with respect to $\mathrm{p}_{1}$. The first-order condition yields

$$
\mathrm{p}_{1}=\left[\mathrm{a}+\mathrm{bp}_{2}{ }^{*}\right] / 2 \mathrm{~b}
$$

Substitute (4) into (2):

$$
\pi_{2}^{*}=\left[p_{2}^{*}-c^{e}\right]\left[a-b p_{2}^{*}\right] / 2
$$

The board's choice of $\mathrm{p}_{2} *$ arises from its own first-order condition

$$
\mathrm{p}_{2}^{*}=(\mathrm{a}+\mathrm{bc}) / 2 \mathrm{~b}
$$

To see how expected costs affect the developer's profits, substitute (4) and (6) into (3):

$$
\pi_{1}=\left[a-b c^{e}\right]^{2} / 16 b
$$

The lower the expected costs, the lower the fee charged by the zoning board and the higher the developer's profits. The developer will set $c^{e}=c^{L}$, but after the board approves the project, he is as likely to pick the high-cost plan as the lowcost one, since the board pays. Suppose that he picks the high-cost plan. The board will lose money if the spread between the cost plans is great enough; if $\mathrm{c}^{\mathrm{H}}>$ $\mathrm{a} / 2 \mathrm{~b}$ and $\mathrm{c}^{\mathrm{H}}>(3 / 2) \mathrm{c}^{\mathrm{L}}$.

If we allow for bribes, the developer would prefer the high-cost plan, because he could extract a side payment from the board in exchange for an agreement to adopt the low-cost plan. If $\left(\mathrm{c}^{\mathrm{H}}-\mathrm{c}^{\mathrm{L}}\right)$ is large, then the potential side payment is large-and so is the developer's incentive to mislead the board about expected costs. When $\left(\mathrm{c}^{\mathrm{H}}-\mathrm{c}^{\mathrm{L}}\right)$ is large enough-or when demand for the developer's project is very responsive to price-the developer might profit more from the side payment than from the project itself.

In the short run, the bribe can enhance efficiency. Given that the developer would otherwise undertake the high-cost project, it is a Pareto improvement for the board to pay him to switch to the low-cost project. In the long run, the bribe might induce too much development. Suppose that the board did not know the demand for projects. The developer of a project that would otherwise lose money could overstate the demand and understate the cost. Once the board had approved the project, the developer could extract a side payment that would more than recoup his loss on the project itself. The outcome would be Pareto inefficient, since the project's net benefits would be negative. 
Many planners would prefer to turn the zoning decision over to the state if it had the resources to determine $c^{\mathrm{e}}$ independent of the developer's machinations. This approach has merit, but it does not distinguish between the absolute advantages of the state and the locality. The locality-rather than the state-knows best the interests of its constituents. And the state-rather than the locality-can exploit scale economies in gathering and analyzing technical data. It would be desirable to assign the decision making to the township and the gathering of technical information to the state, while still encouraging the developer to choose the low-cost plan and discouraging him from understating costs. Now let us consider whether impact fees can satisfy at least some of those conditions.

Case 2: Developer pays some infrastructural costs. Suppose that the board requires the developer to pay, in addition to $\mathrm{p} 2, \mathrm{~s}$ percent of the infrastructural costs. The board will pay (1-s) percent of the costs. The board expects to gain

$$
\pi_{2}^{\mathrm{e}}=\left[\mathrm{p}_{2}-(1-\mathrm{s}) \mathrm{c}^{\mathrm{e}}\right]\left[\mathrm{a}-\mathrm{bp} \mathrm{p}_{1}\right]
$$

The developer's profit would be

$$
\pi_{1}=\left[\mathrm{p}_{1}-\mathrm{sc}-\mathrm{p}_{2}\right]\left[\mathrm{a}-\mathrm{bp}_{1}\right]
$$

The zoning board charges $\mathrm{p}_{2}$. The developer chooses $\mathrm{p}_{1}$ to maximize (9) subject to $\mathrm{p}_{2}=\mathrm{p}_{2} *$. The first-order condition yields

$$
\mathrm{p}_{1}=\left[\mathrm{a}+\mathrm{bsc}+\mathrm{bp}_{2} *\right] / 2 \mathrm{~b}
$$

The developer's price rises with the board's fee and with the costs that he must bear. The board expects the developer to charge

$$
\mathrm{p}^{\mathrm{e}}=\left[\mathrm{a}+\mathrm{bsc}^{\mathrm{e}}+\mathrm{bp}_{2}{ }^{*}\right] / 2 \mathrm{~b}
$$

Substitute (11) into (8):

$$
\pi_{2}^{\mathrm{e}}=\left[\mathrm{p}_{2}-(1-\mathrm{s}) \mathrm{c}^{\mathrm{e}}\right]\left[\mathrm{a}-\mathrm{bsc} \mathrm{e}^{\mathrm{e}}-\mathrm{bp}_{2}\right] / 2
$$

The board chooses $\mathrm{p}_{2}$ to maximize (12). The first-order condition yields

$$
\mathrm{p}_{2}{ }^{*}=\left[\mathrm{a} / \mathrm{b}+(1-2 \mathrm{~s}) \mathrm{c}^{\mathrm{e}}\right] / 2
$$

From (13), $\mathrm{dp}_{2}{ }^{*} / \mathrm{dc}^{\mathrm{e}}=(1-2 \mathrm{~s}) / 2$. Suppose that expected infrastructural costs rise. When the board shoulders most infrastructural costs $(s<.5)$, it will raise $p_{2}$. When the developer pays most infrastructural costs $(\mathrm{s}>.5)$, the board will lower $\mathrm{p}_{2}$. These dual results are due to the price elasticity of the demand that the developer faces. When the developer pays most infrastructural costs, he must raise his unit price into the highly elastic region of his linear demand curve. When, on top of that, he must raise his price to cover an increase in the board's 
location fee, the number of sites sold drops sharply. Fee revenues also drop, and the board suffers a net loss despite its higher fee.

Now we can take stock. When the developer must pay more than half of the costs $(1 \geq s>.5)$, he has an incentive to overstate the costs, since this will cause the board to lower its fee. If he pays exactly half the costs $(s=.5)$, he has no incentive to lie, since the zoning fee will be $\mathrm{a} / 2 \mathrm{~b}$, no matter what he says.

What if the developer pays less than half of the costs? We have already considered the case when $\mathrm{s}=0$. Now suppose that $0<\mathrm{s}<.5$. The developer will adopt $c^{L}$. But, he cannot understate this level because it is the minimum. By telling the truth, setting $c^{e}=c^{L}$, the developer will secure the lowest possible location fee.

In sum, the developer will understate costs only if he pays no share of them. Otherwise, he will state costs accurately or overstate them.

The board will not approve a project that it expects to go bankrupt. Thus, when the developer overstates costs, he must be careful not to overdo it. His statement of $c^{e}$ must satisfy

$$
\pi_{1}^{\mathrm{e}}=\left[\mathrm{p}_{1}^{\mathrm{e}}-\mathrm{sc}^{\mathrm{e}}-\mathrm{p}_{2}\right]\left[\mathrm{a}-\mathrm{bp}_{1}^{\mathrm{e}}\right] \geq 0
$$

Substituting for $\mathrm{p}_{1}^{\mathrm{e}}$ and $\mathrm{p}_{2}$,

$$
\left[a-2 b c^{e}\right]\left[4 a b-3 a-b c^{e}\right] \geq 0
$$

From (15), we can deduce three cases:

$$
\begin{array}{lll}
0<c^{e}<a / 2 b & \Rightarrow & \pi_{1}^{e}>0 \\
c^{e}=a / 2 b & \Rightarrow & \pi_{1}^{e}=0 \\
a / 2 b<c^{e} & \Rightarrow & \pi_{1}^{e}<0
\end{array}
$$

The developer's expected profits are non-negative only if ce $\leq a / 2 b$.

What about the board's expected profits? By substituting (13) into (12):

$$
\left.\pi_{2}^{\mathrm{e}}=[\mathrm{a}-\mathrm{bc}]^{\mathrm{e}}\right]^{2}[1 / 8 \mathrm{~b}]
$$

The board's expected profits do not depend on its share of the costs, since it simply raises its location fee to cover an increased share of the expected costs. (From (13), $\left.\mathrm{dP}_{2} / \mathrm{ds}=-c e.\right)^{11}$

To compute the developer's actual profits, use (10) and (13):

$$
\pi_{1}=\left[a / 2-b s c-b(1-2 s) c^{e} / 2\right]^{2}[1 / 4 b]
$$


TABLE 1

Developer's Choice of Expected Cost and Actual Cost in 12 Scenarios

\begin{tabular}{|c|c|c|c|}
\hline Cost Level & $s=0$ & $0<s \leq .5$ & $.5<\mathrm{s} \leq 1$ \\
\hline $\begin{array}{l}c^{\mathrm{H}} \leq \mathrm{a} / 2 \mathrm{~b} \\
\mathrm{c}^{\mathrm{L}} \geq \mathrm{a} / 2 \mathrm{~b}\end{array}$ & $\begin{array}{l}\text { set } c^{e}=c^{L} \\
\text { adopt } c^{H}\end{array}$ & $\begin{array}{l}\text { set } c^{e}=c^{L} \\
\operatorname{adopt} c^{L}\end{array}$ & $\begin{array}{l}\text { set } c^{e}=c^{H} \\
\text { adopt } c^{L}\end{array}$ \\
\hline $\begin{array}{l}c^{\mathrm{H}} \leq \mathrm{a} / 2 \mathrm{~b} \\
\mathrm{c}^{\mathrm{L}} \leq \mathrm{a} / 2 \mathrm{~b}\end{array}$ & $\begin{array}{l}\text { set } c^{e}=c^{L} \\
\operatorname{adopt} c^{H}\end{array}$ & $\begin{array}{l}\text { set } c^{e}=c^{L} \\
\text { adopt } c^{L}\end{array}$ & $\begin{array}{l}\text { set } c^{e}=a / 2 b \\
\text { adopt } c^{L}\end{array}$ \\
\hline $\begin{array}{l}c^{H}>a / 2 b \\
c^{L}>a / 2 b\end{array}$ & no project & no project & no project \\
\hline
\end{tabular}

Symbols: $c^{e}=$ expected cost

$c^{\mathrm{H}}=$ high-cost option

$c^{L}=$ low-cost option

$s=$ the cost share that the developer will pay

Table 1 is constructed from (17) and (18) and describes the developer's selection of $c^{e}$ and c. Simulations suggest that, by levying impact and location fees, the board can command the lion's share of the profits from the developer's project. $^{12}$

In sum, the analysis suggests that when the developer must pay some costs, he will not understate them and he will not fail to minimize them (for a given level of output). He will also eschew projects with very high infrastructural costs.

Jurisdictional competition. From (17), the board never expects to lose money from any project that it approves. However, expected gains might induce other jurisdictions to compete for the project by offering lower location fees. In the event of perfect competition among jurisdictions, the board must take $\mathrm{p}_{2}$ as given. Its decision on the project is subject to the constraints that it takes the competitive price, $\mathrm{p}^{* *}$, and that its gain is nonpositive:

$$
\pi_{2}{ }^{* *}=\left[\mathrm{p}_{2}{ }^{* *}-(1-\mathrm{s}) \mathrm{c}^{\mathrm{e}}\right]\left[\mathrm{a}-\mathrm{bsc}^{\mathrm{e}}-\mathrm{bp}_{2}{ }^{* *}\right] / 2 \leq 0
$$

From (19), $\mathrm{p}_{2}{ }^{* *}=(1-\mathrm{s}) \mathrm{c}^{\mathrm{e}}{ }^{13}$ The competitive location fee just covers the jurisdiction's expected costs. If the developer must pay all infrastructural costs of his project $(s=1)$, the competitive location fee will be zero. ${ }^{14}$

When the developer pays no infrastructural costs, he might understate expected costs, forcing the board to pay unexpectedly high actual costs. If the jurisdiction is competitive, its fiscal loss will be particularly sharp, since it cannot charge a location fee. It seems important for the competitive jurisdiction to require the developer to pay some costs. 
Case 3: Developer pays all infrastructural costs. Intuition suggests that it is optimal for the developer to pay all costs, and that requiring him to pay only part of the costs would give him an incentive to produce too much. But in our model, the matter is not that clear. The developer behaves like a monopolist-overpricing and underproducing. If the jurisdiction subsidized part of the developer's cost, he would lower the price and step up production, which would seem to enhance efficiency. However, by assuming part of the developer's costs, the jurisdiction does not really subsidize him. Instead, it raises its zoning fee accordingly.

This section will find the developer's share of costs (s) that will minimize the loss of consumer surplus (LCS) that is due to the developer's exercise of market power.

The competitive equilibrium is $\left(c^{L}, a-b c^{L}\right)$. Suppose that the monopoly equilibrium is $\left(\mathrm{P}_{1}, \mathrm{D}_{1}\right)$. The loss of consumer surplus is

$$
\mathrm{LCS}=[\mathrm{b} / 2]\left[\mathrm{P}_{1}-\mathrm{C}^{\mathrm{L}}\right]^{2}
$$

Rewriting $\mathrm{P}_{1}$ as a function of $\mathrm{s}$ :

$$
\begin{aligned}
& d L C S / d s=\left(d L C S / d P_{1}\right)\left(d P_{1} / d s\right) \\
& =(b / 2)\left[P_{1}-c^{L}\right]\left[c^{L}-c^{H}\right]<0 \text { when } c^{e}=c^{H} \\
& =(b / 2)\left[P_{1}-c^{L}\right]\left[c^{L}-c^{H}\right]=0 \text { when } c^{e}=c^{L}
\end{aligned}
$$

The loss of consumer surplus is minimized by $s=1$. If the zoning board is uncertain about the developer's costs, then the welfare loss due to his exercise of market power is minimized by requiring him to pay all infrastructural costs.

Developers argue that impact fees will force them to raise prices. However, the analysis suggests that by coupling a location fee with the impact fee, the board can induce the developer to lower his own price even while raising his impact fee to levels that increase consumer surplus. ${ }^{15}$

Although the board can increase consumer surplus, the model does not necessarily suggest that it will. To maximize net tax revenues for current residents, the board would select any value of $s \in(0, .5)$. Curiously, the developer-not the board-would gain from securing the value of $s$ that minimized welfare loss. When $s>0$, the value of $s$ that maximizes his profits is 1 . Why? Suppose that the board raises $\mathrm{s}$. To compensate, it will lower its location fee by $c^{\mathrm{e}}$, the amount by which the board expects the developer's unit costs to increase. But when $\mathrm{s}>0$, the developer does not understate costs. Indeed, when $s>.5$, he will overstate them. In that event, his costs will fall and his profits will rise. The board's net tax revenues will fall, since it lowered its location fee too much. So the board will 
maximize revenues by setting $\mathrm{s}$ no higher than .5 , where the developer will not overstate costs. $^{16}$

Often the developer cannot control costs, although he knows more about them than the board. Suppose that the project's infrastructural costs were so high that the board would lose money by paying all of them-but it would expect to make money if it thought that costs would be low. The developer might understate costs to gain the board's approval. Under these circumstances, would an impact fee still make a difference?

Let $\mathrm{c}=\mathrm{c}^{\mathrm{H}}$. Let $\pi^{\mathrm{e}}{ }_{2}>0$ when $\mathrm{c}^{\mathrm{e}}=\mathrm{c}^{\mathrm{L}}$ but $\pi_{2}<0$ when $\mathrm{c}=\mathrm{c}^{\mathrm{H}}$, while $\pi_{1}>0$. Then one can show that when the board requires the developer to pay at least half the infrastructural costs, the developer will not understate the costs, since that would cause the board to raise its location fee.

\section{PRICES AND PROPERTY RIGHTS}

The model is normative. It assumes that the board tries to maximize "profits," and then divides them among current residents. Some scholars suggest that the purpose of zoning is to increase either the property values or the welfare of the community's current residents. Suppose that welfare could be measured in monetary units. Then one might represent the broader purpose of zoning as increasing the wealth of current residents. That is the motivation for the assumption of profit-maximization.

The assumption is most relevant when the zoning board can charge a fee per unit of development. Fischel (1985) has challenged this assumption in a broader context. He argues that democracies will not permit unlimited sales of regulatory exceptions because governments would profit from passing as many regulations as possible and then selling the exceptions. Consequently, it is unrealistic to assume that communities will permit their zoning boards to charge a location fee. Perhaps the zoning economist should eschew the standard optimization model for an analysis based on attenuated property rights.

Fischel is perceptive in stressing the importance of property rights to zoning analyses. However, when jurisdictions compete, they are constrained from exercising market power in the form of overregulation. Although additional legal constraints are not necessary, of course, legal constraints can be substituted for jurisdictional competition. That is, we can always allow the zoning board to retain market power and then try to compel the board by legal means not to use that power. But in many cases we would prefer competition because it entails lower transaction costs. 
Cumberland (1990) has raised another important objection to the idea that the zoning board can maximize a proxy variable for community welfare. He argues that "local planning and zoning authorities are typically dominated economically and politically by the construction industry." In that case, the board would not impose impact fees as a general policy, since that would damage its masters' interests. In terms of our model, the developer would set $\mathrm{p}_{1}=\mathrm{a} / 2 \mathrm{~b}$ and $\mathrm{p}_{2}=0$, imposing greater costs on the community than in the case that required him to pay impact fees.

One can readily find allegations of zoning boards dominated by developers. In the early 1970s, Florida's Collier County made little attempt to protect the Big Cypress swamp (a recharge area for the water aquifer) from the encroachments of development. Carter (1974) attributes much of Collier's lassitude to the ties of county officials to land developers.

If the problem is that certain interest groups dominate government, then perhaps the best approach is a direct one: support countervailing interest groups who would monitor local zoning authorities and publicize their activities. Tideman (1969) found that in Cicero, Illinois, zoning officials usually rejected commercial or industrial proposals when three or four neighbors objected. While these rejections are not necessarily Pareto improvements, they do illustrate the power of a countervailing interest group.

Government support of interest groups is a sensitive issue, and it would be desirable to find an efficiency-enhancing means of doing it. Perhaps governments could subsidize innovations in acquiring and transmitting information, making it easier to form countervailing groups.

It is unlikely that a competitive market can provide the optimal amount of innovation, since the innovator cannot capture all the rents from his product. The subsequent lack of innovation makes it costly and difficult to form large, heterogeneous interest groups, which might justify government subsidies.

\section{CONCLUSIONS}

Zoning reduces the transaction costs of bargaining. The developer can negotiate with one zoning board, rather than with large, diverse groups of residents. However, the developer might mislead the board ex ante about those effects. Suppose that the board agrees to pay all infrastructural costs of the proposed project. Then the developer might understate those costs in order to trick the board into approving a project that it would otherwise deny. The resulting fiscal loss could be heavy for the community, particularly if it must compete with its neighbors for economic development. Competition would prevent it from extract- 
ing a location rent from the project that could cover unexpectedly large infrastructural costs.

Suppose that the developer can choose to adopt a low-cost infrastructural plan rather than a high-cost one. Initially, he might seem indifferent about the two plans, since the board pays all costs in either case. However, in an unrepeated game, he might profit by understating costs in order to gain project approval and then threatening to adopt the high-cost plan instead. In this manner, he could extract a bribe from the board in exchange for returning to the low-cost plan.

The board might avoid such pitfalls by requiring the developer to pay some infrastructural costs. The analysis here, which assumes a linear demand function for the developer's project, suggests that the board can best avoid the information problem by requiring the developer to pay at least half the infrastructural costs.

The analysis assumes a rural setting, but extensions to an urban setting might also be useful. Three areas for future research are suggested by the analysis:

First, the analysis assumes that the average costs of infrastructure are constant. This assumption seems unrealistic in an urban setting because over a relevant range, average costs fall as population density increases.

Second, the analysis assumes that the board and the developer take $\mathrm{s}$ as given (it might be a legal constraint), and look at how various values of $s$ affect the distribution of profits. In an urban setting where the board and the developers play repeated games, they might negotiate $s$ itself.

Third, several recent important contributions to the theory of regulatory policy under limited information suggest applications to land-use policy. Lewis and Sappington (1988) investigate the policy of a regulator with imperfect information about the firm's cost and demand functions. The model might shed light on those cases in which the rural zoning board knows little about housing demand or construction costs. Laffont and Tirole (1986) consider the regulator's use of accounting data when the firm knows more about cost than the regulator and invests in cost reduction.

Despite its limitations, this analysis should suggest the value of applying regulatory and industrial organization theory to zoning issues. Traditionally, they have been analyzed through case studies and legal arguments. A more abstract and economic approach might yield additional insights.

\section{ENDNOTES}

1. More generally, advocates of development might have an incentive to misstate the costs and benefits of their proposals. In the 1980s, the Dallas Area Rapid Transit used "clearly unrealistic" land-use forecasts and "optimistic" rider- 
ship forecasts to try to persuade voters to approve a 91 -mile rapid rail system (Kain 1990). DART's referendum failed.

2. One state might compete with other states for a project, but if the intensity of competition increases with the number of rivals, then competition between states typically will be less intense than competition between communities.

3. This paper abstracts from an interesting issue: What if the developer or the board is tempted to renege on the agreement?

4. The board picks the impact fee before the development fee because it sets the impact fee to try to induce developers not to understate costs. Presumably, all developers want to shade the truth, so the impact fee need not vary from one project to another. The development fee extracts locational rent, which can vary from one project to another.

5. An analysis of a repeated game could pertain to metropolitan zoning. Here I consider a rural jurisdiction that must grapple with a single large project.

6. This model bears a family resemblance to the duopoly model of static price competition under asymmetric information (Tirole 1988). Recently, the planning literature has viewed the planner as the developer's "partner" (Catanese and Snyder 1988). A duopoly model is indicated.

7. The assumption of a linear demand function is restrictive, but it permits sharp results.

8. The model assumes constant returns to scale to infrastructural construction. In reality, cost technologies vary from one form of infrastructure to another, but for a stylized representation of all infrastructure, assuming constant returns does not seem unreasonable. Apparently, there are constant returns to the construction of highway miles (Keeler and Small 1977; Kraus 1981). Additions to schools, measured in usable square feet, seem subject to constant or decreasing returns. The construction of a new school, measured in usable square feet, seems subject to increasing returns until the school occupies all available land; then decreasing returns set in as the school is built upward rather than outward.

Generally speaking, the average cost of urban infrastructure falls as one increases the density of development, holding constant the size of the population served (Kirwan 1989). The zoning board can possibly make two decisions: whether to approve a project of given size, or what minimum lot size to select in order to induce density. This paper addresses the first issue.

9. The reader can obtain from the author the proof for this proposition as well as for others unproved by the text.

10. A pathological fourth case exists: If $c^{e} \geq a(4 b-3) / b$, then $\pi_{e} 1 \geq 0$. But in truth, the developer will not undertake a project where unit costs exceed $\mathrm{a} / \mathrm{sb}$, since this would force him to charge a price so high that demand would go to zero. It is straightforward to show that if $b>1$, then $a / s b<a(4 b-3) / b$. 
11. The model is normative. But one positive test is to regress the jurisdiction's tax revenues on $\mathrm{s}$ and see whether the coefficient is zero. To test this proposition, a cross-community study might be employed to focus on recently constructed residential projects. It might estimate $s$ as the ratio of the road impact fee to the total cost of road construction required by the project, and then regress property tax revenues upon this proxy for $\mathrm{s}$.

12. The results of a simulation that describe the distribution of profits between the developer, board, and consumers are available from the author.

13. Note that $\mathbf{p}_{2}{ }^{* *}=a / b-s c^{e}$ is not feasible. It ensures that demand for zoning sites will be zero.

14. A referee notes that regional development strategy often sets $\mathrm{s}<0$.

15. I have not said much about how to ensure that the developer lives up to his agreement to pay some share of the infrastructural costs. Whether the issue is interesting depends largely on when the developer gets his money. If he is paid after the project is completed, then it is in his best interest to ensure that the community completes the infrastructure, even if he has to pay for it himself. But if he is paid up front, then he has an incentive to renege on his commitment to the community. To cope, the board might require him to pay his share of each infrastructural unit as it is constructed, plus an amount that would compensate the board for having to tear up the infrastructure if the developer reneged on paying for future units. This speculative compensation would accumulate in an escrow account that would be repaid to the developer, at the appropriate rate of interest, when the infrastructure is completed.

16. The developer would prefer to pay all the infrastructural costs, incidentally minimizing the loss of consumer surplus. The board would increase net tax revenues by paying at least half, but not all, the infrastructural costs itself, since this would remove the developer's incentive to overstate expected costs. If this were a repeated game, the board eventually would learn that $s \in(0, .5]$ maximized its actual net revenues. The structure of the problem would change. But a repeated game is not in the spirit of the analysis, which particularly concerns a rural jurisdiction that faces one big project.

\section{REFERENCES}

Besanko, David, and David E.M. Sappington. Designing Regulatory Policy With Limited Information. New York: Harwood Academic Publishers, 1987.

Carter, Luther J. The Florida Experience: Land and Water Policy in a Growth State. Baltimore: Johns Hopkins University Press, 1974. 
Catanese, Anthony J., and James C. Snyder. Urban Planning. 2nd ed. New York: McGraw Hill, 1988.

Cumberland, John H. "Rublic Choice and the Improvement of Policy Instruments for Environmental Management." Ecological Economics 2 (1990): 149-162.

Fischel, William A. "Fiscal and Environmental Considerations in the Location of Firms in Suburban Communities." In Fiscal Zoning and Land Use Controls, pp. 119-74. Edited by Edwin S. Mills and Wallace E. Oates. Lexington, Mass.: D.C. Heath, 1975.

The Economics of Zoning Laws: A Property Rights Approach to American Land Use Controls. Baltimore: Johns Hopkins University Press, 1985.

Healy, Robert G. Land Use and the States. 1st ed. Baltimore: Johns Hopkins University Press, 1976.

Kain, John F. "Deception in Dallas: Strategic Misrepresentation in Rail Transit Promotion and Evaluation." APA Journal 56 (1990): 184-196.

Keeler, Theodore E., and Kenneth A. Small. "Optimal Peak-Load Pricing, Investment and Service Levels on Urban Expressways." Journal of Political Economy 85 (1977): 1-25.

Kirwan, Robert M. "Finance for Urban Public Infrastructure." Urban Studies 26 (1989): 285-300.

Kraus, Marvin. "Scale Economies Analysis for Urban Highway Networks." Journal of Urban Economics 9 (1981): 1-22.

Laffont, Jean-Jacques, and Jean Tirole. "Using Cost Observation to Regulate Firms." Journal of Political Economy 94 (1986): 614-641.

Lewis, Tracy R., and David E.M. Sappington. "Regulating a Monopolist with Unknown Demand and Cost Functions." Rand Journal of Economics 19 (1988): 438-457.

Oates, Wallace E., and Robert M. Schwab. "Economic Competition Among Jurisdictions: Efficiency Enhancing or Distortion Inducing?" Journal of Public Economics 35 (1988): 333-354.

Sappington, David E.M., and Joseph E. Stiglitz. "Information and Regulation." In Public Regulation: New Perspectives on Institutions and Policies, pp. 3-44. Edited by Elizabeth E. Bailey. Cambridge, Mass.: The MIT Press, 1987.

Tideman, T. Nicolaus. "Three Approaches to Improving Urban Land Use." Ph.D. diss., University of Chicago, 1969.

Tirole, Jean. The Theory of Industrial Organization. Cambridge, Mass.: The MIT Press, 1988. 